\begin{tabular}{|l|l|}
\hline Jurnal Bimbingan dan Konseling Ar-Rahman \\
Volume 6, Nomor 2, Tahun 2020 \\
Tersedia Online: http://ojs.uniska.ac.id/index.php/BKA \\
e-ISSN 2477-6300
\end{tabular}

\title{
PERAN LITERASI KESEHATAN MENTAL TERHADAP INTENSITAS PERILAKU PENCARIAN PERTOLONGAN DI KALANGAN ANAK JALANAN KOTA PALEMBANG
}

\author{
Indra Prapto Nugroho, Angeline Hosana Zefany Tarigan, Muhammad Zainal Fikri \\ Program Studi Psikologi, Fakultas Kedokteran, Universitas Sriwijaya \\ E-mail: ipnugroho@fk.unsri.ac.id
}

\begin{abstract}
ABSTRAK
Penelitian ini bertujuan untuk mengetahui apakah ada peran literasi kesehatan mental terhadap intensitas perilaku pencarian pertolongan pada anak jalanan di kota Palembang. Hipotesis penelitian ini adalah ada peran literasi kesehatan mental terhadap intensitas perilaku pencarian pertolongan. Penelitian ini menggunakan partisipan sebanyak 200 anak jalanan berusia 6-17 tahun yang masih memiliki keluarga dan bekerja di jalanan kota Palembang serta menggunakan 50 anak jalanannya sebagai partisipan uji coba. Teknik sampling yang digunakan adalah insidental sampling. Alat ukur yang digunakan adalah skala literasi kesehatan mental dan perilaku pencarian pertolongan. Analaisis data yang digunakan adalah regresi linier sederhana. Hasil analisis regresi menunjukkan nilai $\mathrm{R}$ square $=0,307, \mathrm{~F}=65,645$, dan $\mathrm{p}=0,000$. Hal ini menunjukkan bahwa literasi kesehatan mental memiliki peran signifikan terhadap intensitas perilaku pencarian pertolongan. Dengan demikian, hipotesis penelitian dapat diterima, di mana kontribusi literasi kesehatan mental terhadap intensitas perilaku pencarian pertolongan ialah sebesar 30,7\%.
\end{abstract}

Kata Kunci: Perilaku Pencarian Pertolongan; Kesehatan Mental; Literasi; Anak Jalanan

\begin{abstract}
This study aims to determine whether there is a role of mental health literacy toward help seeking behaviour intensity among street children in Palembang City. The hypotheses is there is a role of mental health literacy toward help seeking behaviour intensity. This study used 200 street children as participants with age between 6-17 years old who still has family and works on the Palembang city's street and also used 50 street children as trial participants. The sampling technique was incidental sampling. The measurements used mental health literacy and help seeking behaviour scale. The data analysis used simple linier regression. The result of regression shows the value of $R$ square $=0,307, F=65,645$, and $p=0,000$. This means that mental health literacy has a significant role toward help seeking behaviour intensity. Thus, the study hypotheses is accepted, which the contribution of mental health literacy toward help seeking behaviour intensity is $30,7 \%$.
\end{abstract}

Keywords: Help Seeking Behavior;Mental Health; Literacy; Street Children

Dipublikasikan Oleh :

UPT Publikasi dan Pengelolaan Jurnal

Universitas Islam Kalimantan Muhammad Arsyad Al-Banjari Banjarmasin 
Indra Prapto Nugroho, Angeline Hosana Zefany Tarigan, Muhammad Zainal Fikri

Jurnal Bimbingan dan Konseling Ar-Rahman

Volume 6, Nomor 2, Tahun 2020

e-ISSN 2477-6300

\section{PENDAHULUAN}

Dewasa ini banyak orang tua yang tidak dapat memenuhi hak dan kebutuhan yang seharusnya didapatkan oleh anak. Hal ini dikarenakan orang tua tidak mampu untuk menghidupi kebutuhan keluarga dan mengakibatkan anak harus merasakan pahitnya bekerja di jalanan. Kondisi yang mendesak akibat kebutuhan ekonomi memunculkan permasalahan sosial yakni lahirnya anak jalanan (Vina, 2019).

Fenomena anak jalanan adalah salah satu permasalahan yang cukup kompleks bagi negara Indonesia. Menurut The United Nations Children's Fund (UNICEF, 2001) anak jalanan merupakan anak-anak yang bekerja atau tidur di jalanan. Berita media kabar digital yang ditulis oleh Pamungkas dan Wisnu (2018) menyatakan bahwa terdapat 16.000 anak jalanan yang tersebar di kota Indonesia. Salah satu daerah yang berkontribusi cukup besar terhadap jumlah anak jalanan adalah kota Palembang yang memiliki 1.278 anak putus sekolah dan anak jalanan (Rio, 2019).

Stasiun, halte bis, trotoar, hingga pasar merupakan lokasi favorit bagi anak jalanan. Keberadaannya yang cukup menjamur membuat anak jalanan rentan terhadap perlakuan yang negatif. Perlakuan yang sering dialami oleh anak jalanan terdiri dari pengusiran dan kekerasan dari masyarakat sekitar (Kaiser, 2020). Berbagai perlakuan yang didapat bagi pekerja anak jalanan di antaranya kekerasan fisik maupun psikis, membuat mereka sering merasa tertekan (Wardani, 2018).

Perilaku eksploitasi yang kerap didapatkan oleh anak jalanan memicu stressor yang akan berimbas kepada gangguan perilaku sosial keseharian mereka (Nihayah \& Legowo, 2016). Selain itu, bagaimana bisa mereka mendapatkan makanan yang layak, dukungan sosial yang memadai, serta edukasi yang mumpuni untuk menunjang kehidupan mereka di masa depan, jika sebagian besar waktu mereka dihabiskan hanya untuk mencari uang demi kepentingan berbagai pihak (Astri, 2014).

Pengalaman-pengalaman tersebut seharusnya dapat ditangani dengan baik oleh negara. Hal ini mengacu kepada Undang-Undang Nomor 36 Tahun 2009 tentang kesehatan di mana setiap warga negara Indonesia berhak mendapatkan pelayanan kesehatan yang baik mencakup usaha promotif, preventif, dan rehabilitasi. Namun, anak jalanan sendiri kerap kali menjadi kalangan yang memiliki akses kesehatan kurang baik sehingga menyebabkan kebutuhan fisik, mental, dan sosial mereka menjadi tidak terpenuhi (Bah, 2018).

Minimnya akses anak jalanan terhadap fasilitas kesehatan sejatinya merupakan hal yang kasuistik. Hal tersebut karena anak jalanan memiliki sumber daya, pengetahuan, waktu, dan kepercayaan yang kurang terhadap penyedia jasa kesehatan dimana hal ini mengakibatkan terjadinya penggunaan zat-zat

adiktif oleh anak jalanan sebagai strategi koping mereka untuk meredakan masalah kesehatan yang mereka alami (Eshita, 2018).

Selain itu, minimnya akses anak jalanan terhadap fasilitas kesehatan serta penggunaan strategi koping yang destruktif mengindikasikan kurang baiknya perilaku pencarian pertolongan oleh anak jalanan. Perilaku pencarian pertolongan sendiri dapat

diartikan sebagai setiap usaha mencari pertolongan dari fasilitas kesehatan atau orang-orang terpercaya ketika

individu mengalami situasi yang sulit (Umubyeyi et al., 2016).

Rendahnya upaya seseorang untuk melakukan pencarian pertolongan disebabkan oleh kurangnya kesadaran yang diduga dapat diprediksi oleh seberapa baik tingkat pemahaman literasi kesehatan mental (Andersson et al., 2013; Fox et al., 2001; Sun et al., 2016). Literasi kesehatan mental sendiri mengacu kepada pengetahuan dan kepercayaan individu mengenai masalah mental (Kutcher, Wei, \& Coniglio, 2016). Literasi kesehatan mental dibutuhkan untuk mengidentifikasi masalah mental sejak dini agar individu dapat mencari pertolongan yang tepat dan sesegera mungkin (Tay, Tay, \& Klainin-Yobas, 2018). Oleh sebab itu, literasi kesehatan mental merupakan faktor penting untuk meningkatkan kesehatan individu serta populasi (Wei, McGrath, Hayden, \& Kutcher, 2015).

Urgensi di atas membuat peneliti tertarik untuk mengetahui seberapa besar peran literasi kesehatan mental terhadap perilaku pencarian pertolongan pada anak jalanan di kota Palembang. Perbedaan penelitian ini dengan penelitian terdahulu terletak pada subjek anak jalanan dan teori komponen literasi kesehatan mental milik Campos, Dias, Palha, Duarte, dan Veiga (2016) yang belum pernah di adaptasi sebelumnya di Indonesia. Komponen tersebut paling tepat digunakan untuk mengevaluasi dan mengembangkan intervensi kesehatan mental pada individu berusia remaja sehingga lebih sesuai dengan rancangan penelitian ini.

\section{METODE}

Metode penelitian yang digunakan adalah metode penelitian kuantitatif dengan jenis penelitian non-experimental. Populasi dalam penelitian ini adalah anak jalanan di kota Palembang. Namun, tidak diketahui secara pasti 
jumlah anak jalanan di kota Palembang. Adapun teknik yang digunakan dalam penelitian ini adalah nonprobability sampling dengan jenis teknik insidental sampling. Jumlah sampel pada penelitian ini mengacu pada teori Roscoe (Sugiyono, 2017) yang memberikan saran mengenai ukuran sampel bahwa ukuran sampel yang layak digunakan dalam penelitian berkisar 30-500 orang. Oleh karena itu, banyak sampel yang digunakan pada penelitian ini adalah sebanyak 200 orang dengan pembagian 50 partisipan untuk try out dan 150 partisipan untuk pengambilan data.

Pendeskripsian subjek penelitian dilakukan berdasarkan jenis kelamin, usia, dan pendidikan terakhir. Data yang di peroleh berdasarkan jenis kelamin, jumlah subjek laki-laki sebanyak 86 orang dan subjek perempuan sebanyak 64 orang. Kemudian, berdasarkan usia, subjek pada usia kanak-kanak pertengahan dan akhir berjumlah 54 orang, sedangkan subjek pada usia remaja berjumlah 96 orang. Selanjutnya, berdasarkan pendidikan terakhir didapatkan subjek dengan tingkat pendidikan terakhir SD ialah berjumlah 82 orang, SMP sebanyak 60 orang, dan SMA sebanyak 8 orang.

Secara garis besar, teknik pengambilan data dalam penelitian ini adalah menggunakan skala untuk mengumpulkan data primer dengan mengukur literasi kesehatan mental dan pencarian pertolongan formal yang diadaptasi dari alat ukur MHLQ oleh Campos, Dias, Palha, Duarte, dan Veiga (2016) dan skala Help Seeking Behavior yang dibuat oleh peneliti berdasarkan teori dari Liang, Goodman, Tummala-Narra, dan Weintraub (2005).
Berdasarkan analisis, aitem yang dinyatakan valid pada skala literasi kesehatan mental ialah 17 aitem dengan koefisien korelasi aitem pada rentang 0,3170,562 dan reliabilitas sebesar 0,859. Sedangkan, pada skala perilaku pencarian pertolongan didapatkan 27 aitem yang valid dengan koefisien korelasi aitem pada rentang 0,309-0,580 dan reliabilitas sebesar 0,867 .

Uji hipotesis pada penelitian ini menggunakan regresi sederhana yang digunakan untuk peramalan, dimana dalam model tersebut ada variabel dependen atau tergantung dan variabel independen atau bebas.

\section{Hipotesis}

Terdapat peran literasi kesehatan mental terhadap intensitas perilaku pencarian pertolongan.

\section{HASIL DAN PEMBAHASAN}

\section{Deskripsi Data Penelitian}

Dalam penelitian ini, peneliti melakukan analisis deskriptif untuk mendapatkan gambaran terhadap sebaran masing-masing variabel penelitian. Adapun deskripsi data dari dua variabel terdapat pada tabel 1 .

Kemudian, peneliti juga melakukan penggolongan subjek penelitian dalam kategorikategori tertentu. Penggolongan subjek ini dilakukan melalui dua bentuk kategori, yaitu kategori rendah dan kategori tinggi. Dua bentuk penggolongan kategori menggunakan rumusan dapat dilihat pada tabel 2 .

Tabel 1. Deskripsi Data Penelitian

\begin{tabular}{|c|c|c|c|c|c|c|c|c|c|c|}
\hline \multirow{2}{*}{ Variabel } & \multicolumn{5}{|c|}{ Data Hipotetik } & \multicolumn{5}{|c|}{ Data Empiris } \\
\hline & Max & Min & Mean & $\mathrm{SD}$ & Med & Max & Min & Mean & $\mathrm{SD}$ & Med \\
\hline $\begin{array}{l}\text { Literasi Kesehatan } \\
\text { Mental }\end{array}$ & 68 & 17 & 42,5 & 8,5 & 50 & 65 & 34 & 49,48 & 5,38 & 49,56 \\
\hline $\begin{array}{l}\text { Perilaku Pencarian } \\
\text { Pertolongan }\end{array}$ & 108 & 27 & 67,5 & 13,5 & 73,5 & 104 & 47 & 75,72 & 9,81 & 71 \\
\hline
\end{tabular}

Tabel 2. Formulasi Kategorisasi

\begin{tabular}{cl}
\hline Kategori & Formulasi \\
\hline Rendah & $\mathrm{X}<$ Median \\
Tinggi & Median $\leq \mathrm{X}$ \\
\hline
\end{tabular}

Tabel 3. Deskripsi Kategorisasi Perilaku Pencarian Pertolongan

\begin{tabular}{|c|c|c|c|}
\hline Formula & Kategori & Frekuensi & Persentase \\
\hline$X<71$ & Rendah & 51 & $34 \%$ \\
\hline $71 \leq \mathrm{X}$ & Tinggi & 99 & $66 \%$ \\
\hline \multicolumn{2}{|c|}{ Total } & 150 & $100 \%$ \\
\hline
\end{tabular}


Indra Prapto Nugroho, Angeline Hosana Zefany Tarigan, Muhammad Zainal Fikri

Jurnal Bimbingan dan Konseling Ar-Rahman

Volume 6, Nomor 2, Tahun 2020

e-ISSN 2477-6300

Tabel 4. Deskripsi Kategorisasi Literasi Kesehatan Mental

\begin{tabular}{cccc}
\hline Formula & Kategori & Frekuensi & Persentase \\
\hline $\mathrm{X}<49,56$ & Rendah & 72 & $48 \%$ \\
$49,56 \leq \mathrm{X}$ & Tinggi & 78 & $52 \%$ \\
\hline & & 150 & $100 \%$ \\
\hline
\end{tabular}

Berdasarkan data hasil kategorisasi tersebut, dapat diketahui bahwa pada tabel 3, subjek dengan tingkat perilaku pencarian pertolongan rendah ialah sebanyak 51 orang $(34 \%)$ dan subjek dengan tingkat perilaku pencarian pertolongan tinggi ialah sebanyak 99 orang $(66 \%)$. Kemudian pada tabel 4 menunjukkan bahwa subjek dengan tingkat literasi kesehatan mental rendah ialah sebanyak 72 orang ( $48 \%$ ) dan subjek dengan tingkat literasi kesehatan mental tinggi ialah sebanyak 78 orang $(52 \%)$.

\section{Hasil Analisis Data Penelitian}

Variabel perilaku pencarian pertolongan mendapatkan hasil uji Kolmogorov-Smirnov sebesar 1.338 dan signifikansi sebesar 0,056 ( $p>0,05)$, sehingga dapat disimpulkan bahwa data penelitian pada variabel perilaku pencarian pertolongan berdistribusi dengan normal. Kemudian, hasil uji normalitas pada variabel literasi kesehatan mental menunjukkan hasil uji Kolmogorov-Smirnov sebesar 0,960 dan signifikansi sebesar 0,316 ( $>>0,05)$. Sehingga, dapat disimpulkan bahwa data penelitian pada variabel literasi kesehatan mental juga berdistribusi normal.

Hasil uji linearitas pada variabel perilaku pencarian pertolongan dan literasi kesehatan mental menunjukkan hasil signifikansi linearity sebesar $0,000(\mathrm{p}<0,05)$. Hal ini menunjukkan bahwa korelasi antara variabel perilaku pencarian pertolongan dengan literasi kesehatan mental adalah linear.

Kemudian, uji hipotesis dilakukan untuk melihat peran literasi kesehatan mental terhadap perilaku pencarian pertolongan. Berdasarkan hasil analisis regresi sederhana, dapat diketahui bahwa nilai signifikansinya sebesar $0,000 \quad(\mathrm{p}<0,05)$. Dengan demikian, hipotesis penelitian ini diterima, yaitu terdapat peran literasi kesehatan mental terhadap perilaku pencarian pertolongan. Hasil analisis data juga menunjukkan nilai $\mathrm{R}$ square sebesar 0,307 yang menunjukkan bahwa peran literasi kesehatan mental terhadap perilaku pencarian pertolongan ialah sebesar $30,7 \%$.

Tabel 5. Tabel Rangkuman Hasil Uji Normalitas

\begin{tabular}{lccc}
\hline \multicolumn{1}{c}{ Variabel } & K-SZ & Sig. & Keterangan \\
\hline $\begin{array}{l}\text { Perilaku Pencarian } \\
\begin{array}{l}\text { Pertolongan } \\
\text { Literasi Kesehatan } \\
\text { Mental }\end{array}\end{array}$ & 1,338 & 0,056 & Normal \\
\hline
\end{tabular}

Tabel 6. Tabel Rangkuman Hasil Uji Linearitas

\begin{tabular}{lccc}
\hline \multicolumn{1}{c}{ Variabel } & \multicolumn{2}{c}{ Linearity } & \\
& F & Sig. & Keterangan \\
\hline $\begin{array}{l}\text { Perilaku Pencarian Pertolongan } \\
\text { Literasi Kesehatan Mental }\end{array}$ & 72,051 & 0,000 & Linear \\
\hline
\end{tabular}

Tabel 7. Tabel Rangkuman Hasil Uji Hipotesis

\begin{tabular}{lccccc}
\hline \multicolumn{1}{c}{ Variabel } & R & R Square & F & Sig & Keterangan \\
\hline $\begin{array}{l}\text { Literasi Kesehatan } \\
\text { Mental - Perilaku }\end{array}$ & 0,554 & 0,307 & 65,645 & 0,000 & Terdapat Peran \\
Pencarian Pertolongan & & & & & \\
\hline
\end{tabular}


Indra Prapto Nugroho, Angeline Hosana Zefany Tarigan, Muhammad Zainal Fikri Jurnal Bimbingan dan Konseling Ar-Rahman

Volume 6, Nomor 2, Tahun 2020

e-ISSN 2477-6300

Analisis Tambahan

Tabel 8. Deskripsi Hasil Uji Beda Berdasarkan Jenis Kelamin

\begin{tabular}{lccc}
\hline \multicolumn{1}{c}{ Variabel } & Levene Test & Sig. & Keterangan \\
\hline $\begin{array}{l}\text { Perilaku Pencarian } \\
\begin{array}{l}\text { Pertolongan } \\
\text { Literasi Kesehatan } \\
\text { Mental }\end{array}\end{array}$ & 0,446 & 0,676 & Tidak Ada Perbedaan \\
\hline
\end{tabular}

Peneliti melakukan uji coba T-test pada dua variabel untuk mengetahui ada tidaknya perbedaan pada perilaku pencarian pertolongan dan literasi kesehatan mental pada subjek berdasarkan jenis kelaminnya. Dari tabel di atas, perilaku pencarian pertolongan berdasarkan jenis kelamin diperoleh hasil signifikansi sebesar 0,676 ( $\mathrm{p}<0,05)$, sehingga menunjukkan bahwa tidak terdapat perbedaan perilaku pencarian pertolongan berdasarkan jenis kelamin. Begitu juga dengan hasil signifikansi berdasarkan jenis kelamin pada variabel literasi kesehatan mental yaitu sebesar $0,536(\mathrm{p}<0,05)$ yang berarti juga menunjukkan tidak adanya perbedan.

Tabel 9. Deskripsi Hasil Uji Beda Berdasarkan Usia

\begin{tabular}{lccc}
\hline \multicolumn{1}{c}{ Variabel } & Levene Test & Sig. & Keterangan \\
\hline $\begin{array}{l}\text { Perilaku Pencarian } \\
\begin{array}{l}\text { Pertolongan } \\
\text { Literasi Kesehatan } \\
\text { Mental }\end{array}\end{array}$ & 0,110 & 0,459 & Tidak Ada Perbedaan \\
\hline
\end{tabular}

Tabel 10. Hasil Perbedaan Mean Literasi Kesehatan Mental Berdasarkan Usia

\begin{tabular}{llc}
\hline \multicolumn{1}{c}{ Usia } & N & Mean \\
\hline Kanak-kanak & 54 & 47,76 \\
pertengahan dan akhir & 96 & 50,45 \\
Remaja & 96 \\
\hline
\end{tabular}

Pada tabel 9, peneliti juga melakukan uji beda T-test terhadap kedua variabel untuk mengetahui apakah terdapat perbedaan pada perilaku pencarian pertolongan dan literasi kesehatan mental yang ditinjau dari usia. Hasil uji beda menunjukkan nilai signifikansi pada perilaku pencarian pertolongan sebesar 0,459 $(\mathrm{p}<0,05)$, sehingga menunjukkan bahwa tidak terdapat perbedaan perilaku pencarian pertolongan berdasarkan usia. Kemudian, hasil uji beda pada literasi kesehatan mental menunjukkan nilai signifikansi sebesar 0,003 $(\mathrm{p}<0,05)$. Hal ini berarti terdapat perbedaan literasi kesehatan mental berdasarkan usia. Oleh karena itu, peneliti melakukan analisis tambahan untuk literasi kesehatan mental berdasarkan usia. Deskripsi perbedaan tersebut seperti yang ditunjukkan pada tabel 10. Data tersebut menunjukkan bahwa subjek usia kanak-kanak pertengahan dan akhir memiliki mean sebesar 47,76. Hal ini menandakan bahwa subjek kanak-kanak pertengahan dan akhir memiliki literasi kesehatan mental yang lebih rendah dibandingkan subjek usia remaja.

Tabel 11. Deskripsi Hasil Uji Beda Berdasarkan Pendidikan Terakhir

\begin{tabular}{|c|c|c|c|c|c|}
\hline Variabel & $\begin{array}{c}\text { Pendidikan } \\
\text { Terakhir }\end{array}$ & Mean & $\mathbf{F}$ & Sig. & Keterangan \\
\hline \multirow{3}{*}{$\begin{array}{l}\text { Perilaku Pencarian } \\
\text { Pertolongan }\end{array}$} & SD & 74.18 & \multirow{3}{*}{3.196} & \multirow{3}{*}{0,044} & \multirow{3}{*}{ Ada Perbedaan } \\
\hline & SMP & 78.15 & & & \\
\hline & SMA & 73.25 & & & \\
\hline \multirow{3}{*}{$\begin{array}{l}\text { Literasi Kesehatan } \\
\text { Mental }\end{array}$} & SD & 48.34 & \multirow{3}{*}{4.402} & \multirow{3}{*}{0,014} & \multirow{3}{*}{ Ada Perbedaan } \\
\hline & SMP & 50.72 & & & \\
\hline & SMA & 51.88 & & & \\
\hline
\end{tabular}


Indra Prapto Nugroho, Angeline Hosana Zefany Tarigan, Muhammad Zainal Fikri

Jurnal Bimbingan dan Konseling Ar-Rahman

Volume 6, Nomor 2, Tahun 2020

e-ISSN 2477-6300

Peneliti melakukan uji beda one way anova terhadap kedua variabel untuk mengetahui apakah terdapat perbedaan perilaku pencarian pertolongan dan literasi kesehatan mental pada subjek bila ditinjau dari pendidikan terakhir. Hasil uji beda di atas menunjukkan nilai signifikansi variabel perilaku pencarian pertolongan dan literasi kesehatan mental masing-masing adalah 0,044 $(\mathrm{p}<0,05)$ dan $0,014(\mathrm{p}<0,05)$. Hal ini menunjukkan bahwa terdapat perbedaan pada perilaku pencarian

pertolongan dan literasi kesehatan mental berdasarkan pendidikan terakhir.

Selain itu, data analisis rata-rata (mean) menunjukkan bahwa subjek dengan pendidikan terakhir SMA memiliki perilaku pencarian pertolongan paling rendah, yaitu dengan nilai mean sebesar 73,25. Kemudian, data tersebut juga menunjukkan bahwa subjek dengan pendidikan terakhir SD memiliki literasi kesehatan mental paling randah, yaitu dengan nilai mean sebesar 48,34 .

Tabel 12. Uji Sumbangan Efektif Literasi Kesehatan Mental terhadap Perilaku Pencarian Pertolongan

\begin{tabular}{lc}
\multicolumn{1}{c}{ Komponen Literasi Kesehatan Mental } & Sumbangan Efektif \\
\hline Help seeking and first aid skills & $23,50 \%$ \\
$\begin{array}{l}\text { Pengetahuan/stereotip tentang gangguan } \\
\text { kesehatan mental }\end{array}$ & $-0,12 \%$ \\
Strategi self-help $\quad$ Total & $7,32 \%$ \\
\hline \multicolumn{2}{c}{$\quad 30,7 \%$} \\
\hline
\end{tabular}

Data di atas menunjukkan bahwa literasi kesehatan mental yang memiliki sumbangan terbesar pada peranan literasi kesehatan mental terhadap perilaku pencarian pertolongan ialah komponen help seeking and first aid skills, yaitu sebesar $23,50 \%$.

\section{Pembahasan}

Hasil analisis regresi linier sederhana menunjukkan bahwa nilai korelasi (R) literasi kesehatan mental dan intensitas perilaku pencarian pertolongan adalah 0,554 dengan signifikansi sebesar $0,000(\mathrm{p}<0,05)$. Hal ini berarti terdapat peran literasi kesehatan mental terhadap perilaku pencarian pertolongan. Dengan hasil ini, hipotesis yang peneliti ajukan yaitu ada peran literasi kesehatan mental terhadap perilaku pencarian pertolongan diterima. Hasil ini senada dengan beberapa penelitian sebelumnya, seperti penelitian Gorczynski (2017) yang menunjukkan adanya hubungan yang positif antara literasi kesehatan mental terhadap perilaku pencarian bantuan.

Senada dengan itu, Velasco, Cruz, Billings, Jimenez, dan Rowe (2020) menyatakan bahwa literasi kesehatan mental yang baik merupakan salah satu fasilitator paling relevan terhadap perilaku pencarian pertolongan. Selain itu, Waldmann, Staiger, Oexle, dan Rüsch (2019) menemukan bahwa tingginya literasi kesehatan mental berasosiasi dengan meningkatnya perilaku pencarian bantuan.

Persamaan regresi pada penelitian ini ialah $\mathrm{Y}=25,762+1,010 \mathrm{X}$. Adapun kontribusi variabel bebas literasi kesehatan mental terhadap perilaku pencarian pertolongan adalah 0,307. Dengan kata lain, kontribusi literasi kesehatan mental terhadap perilaku pencarian pertolongan adalah sebesar $30,7 \%$. Hal ini mengindikasikan bahwa terdapat kontribusi variabel lain terhadap perilaku pencarian pertolongan.

Penelitian Nagai (2015) menunjukkan bahwa prediktor perilaku pencarian pertolongan adalah intensi pencarian pertolongan, kebutuhan subjektif, dan dukungan sosial. Velasco, Cruz, Billings, Jimenez, dan Rowe (2020) menyatakan bahwa prediktor perilaku pencarian pertolongan adalah stigma, kepercayaan keluarga, ketidaknyamanan psikologis, dan otonomi.

Hasil analisis sumbangan efektif menunjukkan bahwa komponen help seeking and first aid skills memiliki kontribusi terbesar terhadap perilaku pencarian pertolongan, yaitu $23,5 \%$. Komponen ini mengacu kepada sikap yang menghasilkan perilaku pencarian pertolongan serta kemampuan mendukung orang lain yang memiliki gangguan mental (Campos, Dias, Palha, Duarte, \& Veiga, 2016).

Di sisi lain, perilaku pencarian pertolongan mengacu kepada proses penyelesaian masalah yang melibatkan pihak ketiga sebagai respon dari permasalahan yang tidak dapat diselesaikan (Cornally \& McCarthy, 2010). Oleh karena itu, alasan komponen tersebut merupakan kontributor terbesar adalah fungsinya sebagai pemicu dari munculnya variabel perilaku pencarian pertolongan.

Hasil kategorisasi literasi kesehatan mental menunjukkan 72 responden $(48 \%)$ memiliki literasi 
kesehatan mental rendah dan 78 (52\%) responden memiliki literasi kesehatan mental tinggi. Selain itu, kategorisasi perilaku pencarian pertolongan menunjukkan 51 responden (34\%) memiliki perilaku pencarian pertolongan rendah dan 99 responden $(66 \%)$ memiliki perilaku pencarian pertolongan tinggi. Data ini menunjukkan bahwa anak jalanan di Kota Palembang memiliki literasi kesehatan mental dan perilaku pencarian pertolongan yang baik.

Hasil uji beda yang ditinjau dari pendidikan terakhir menunjukkan bahwa terdapat perbedaan literasi kesehatan mental berdasarkan pendidikan terakhir dimana subjek dengan tingkat pendidikan SD memiliki literasi kesehatan mental paling rendah. Hal ini senada dengan penelitian Von Dem Knesebeck et al (2013) yang menemukan bahwa pendidikan dapat mempengaruhi literasi kesehatan mental, dimana rendahnya pendidikan berhubungan dengan rendahnya pengetahuan prevalensi dan gejala gangguan mental. Selain itu, penelitian Lopez, Sanchez, Killian, dan Eghaneyan (2018) menemukan bahwa tingkat literasi kesehatan mental akan semakin tinggi seiring dengan tingginya tingkat pendidikan.

Kemudian, analisis uji beda juga dilakukan berdasarkan tingkat usia. Hasilnya menunjukkan bahwa terdapat perbedaan literasi kesehatan mental berdasarkan usia, dimana usia kanak-kanak memiliki literasi kesehatan mental yang paling rendah. Menurut Riebschleger, Grove, Cavanaugh, dan Costello (2017), kebanyakan anak-anak memiliki tingkat literasi kesehatan mental yang rendah, dimana mereka tidak memiliki informasi yang akurat. Literasi kesehatan mental pada anak berkaitan dengan pengetahuan orang tua terkait jenis, efektivitas, dan akses terhadap intervensi (Tully, Hawes, Doyle, Sawyer, \& Dadds, 2019).

Hasil analisis uji beda juga menunjukkan bahwa terdapat perbedaan perilaku pencarian pertolongan berdasarkan pendidikan terakhir dimana subjek dengan tingkat pendidikan SMA memiliki perilaku pencarian pertolongan paling rendah. Usia anak jalanan yang memiliki tingkat pendidikan SMA pada penelitian ini berkisar dari 15-17 tahun. Menurut Santrock (2012), rentang usia remaja berkisar antara 12-22 tahun. Oleh karena itu, kategorisasi usia anak jalanan dengan tingkat pendidikan SMA pada penelitian ini merupakan remaja.

Cometto (2014) menyatakan bahwa salah satu faktor munculnya pencarian pertolongan pada remaja adalah persepsi yang baik terhadap tingkat keparahan gangguan serta adanya pengalaman pencarian pertolongan di masa lampau. Dua hal ini nampaknya tidak dimiliki oleh sebagian besar anak jalanan karena anak jalanan tidak memiliki akses fasilitas kesehatan yang baik serta cenderung mengabaikan gangguan yang dirasakan sehingga mereka tidak melakukan pencarian pertolongan (Woan, Lin, \& Auerswald, 2013).

\section{PENUTUP \\ Kesimpulan}

Hasil penelitian ini menunjukkan bahwa terdapat peran literasi kesehatan mental terhadap intensitas perilaku pencarian pertolongan. Dengan demikian, hipotesis penelitian ini dapat diterima, yaitu ada peran literasi kesehatan mental terhadap intensitas perilaku pencarian pertolongan. Kemudian, berdasarkan hasil uji sumbangan efektif menunjukkan bahwa komponen help seeking and first aid skills memberikan sumbangan efektif yang terbesar terhadap intensitas perilaku pencarian pertolongan.

Berdasarkan uji beda yang dilakukan berdasarkan jenis kelamin, usia, dan tingkat pendidikan terakhir, hasilnya menunjukkan bahwa terdapat perbedaan literasi kesehatan mental berdasarkan usia, di mana subjek pada usia kanakkanak pertengahan dan akhir memiliki literasi kesehatan mental yang lebih rendah dibandingkan usia remaja. Kemudian, berdasarkan tingkat pendidikan terakhir juga menunjukkan adanya perbedaan, di mana subjek dengan tingkat pendidikan terakhir SD memiliki literasi kesehatan mental paling rendah, sedangkan subjek dengan tingkat pendidikan terakhir SMA memiliki intensitas perilaku pencarian pertolongan yang paling rendah.

\section{Saran \\ 1. Instansi Pemerintah}

Mengedukasi anak jalanan dan orang tidak mampu terkait kesehatan mental agar kesadaran terhadap kesehatan mental dapat tumbuh. Pembinaan terhadap anak jalanan berkaitan kontributor paling besar dari sumbangan efektif, yaitu komponen help seeking and first aid skills yang mengacu kepada sikap yang dapat menghasilkan perilaku pencarian pertolongan. Pembinaan terhadap orang tidak mampu berkaitan dengan peran orang tua dalam membentuk literasi kesehatan mental pada anak sehingga orang tua anak jalanan juga harus mendapatkan edukasi. Setelah kesadaran tersebut terbentuk, pemerintah dapat memberikan kemudahan akses terhadap fasilitas kesehatan bagi anak jalanan agar dapat memfasilitasi kesadaran mental yang sudah dibentuk sebelumnya.

\section{Instansi Pendidikan}

Memberikan edukasi mengenai pentingnya kesehatan mental serta cara penanganannya, 
Indra Prapto Nugroho, Angeline Hosana Zefany Tarigan, Muhammad Zainal Fikri

Jurnal Bimbingan dan Konseling Ar-Rahman

Volume 6, Nomor 2, Tahun 2020

e-ISSN 2477-6300

terutama pada instansi pendidikan SD dan SMA. Hal ini mengacu kepada hasil penelitian yang menunjukkan bahwa subjek dengan latar belakang pendidikan SD memiliki literasi kesehatan mental paling rendah dan subjek dengan latar belakang pendidikan SMA yang memiliki perilaku pencarian pertolongan paling rendah.

\section{Orang tua Anak Jalanan}

Mengawasi serta menumbuhkan kepedulian anak terhadap kondisi kesehatan mentalnya. Hal ini berkaitan dengan peran penting orang tua dalam membentuk literasi kesehatan mental anak.

\section{Penelitian Selanjutnya}

Sumbangan variabel literasi kesehatan mental terhadap perilaku pencarian pertolongan ialah sebesar 30,7\%. Hal ini menunjukkan bahwa terdapat adanya faktor lain yang mempengaruhi perilaku pencarian pertolongan yang juga dapat diteliti selanjutnya.

\section{REFERENSI}

Aguirre Velasco, A., Cruz, I. S. S., Billings, J., Jimenez, M., \& Rowe, S. (2020). What are the barriers, facilitators and interventions targeting help-seeking behaviours for common mental health problems in adolescents? A systematic review. BMC Psychiatry, 20(1). https://doi.org/10.1186/s12888-020-02659-0.

Andersson, L. M. C., Schierenbeck, I., Strumpher, J., Krantz, G., Topper, K., Backman, G., Van Rooyen, D. (2013). Help-seeking behavior, barriers to care and experiences of careamong persons with depression in eastern cape, south africa. Journal Of Affective Disorders, 151(2), 439-44.

https://doi.org/10.1016/j.jad.2013.06.022.

Astri. (2014). Kehidupan anak jalanan di indonesia : Faktor penyebab, tatanan hidup dan kerentanan berperilaku menyimpang. Pusat Pengkajian, Pengolahan Data Dan Informasi (P3di) Sekretariat, 5, 145-155. https://doi.org/10.46807/aspirasi.v5i2.454

Bah, Y. M. (2018). Drug abuse among street children. Biomedical Journal of Scientific \& Technical Research, 10(4). https://doi.org/10.26717/bjstr.2018.10.0019.

Campos, L., Dias, P., Palha, F., Duarte, A., \& Veiga, E. (2016). Development and psychometric properties of a new questionnaire for assessing mental health literacy in young people. Universitas Psychologica, 15(2), 61-72. https://doi.org/10.11144/Javeriana.upsy152.dppq.
Cometto, J. L. (2014). Factors predicting adolescents' and parents' help seeking behaviour. ProQuest Dissertations and Theses, 300. http://ezproxy.library.usyd.edu.au/login?url =http://search.proquest.com/docview/14967 80577 ?accountid=14757\%5Cnhttp://dd8gh5 yx7k.search.serialssolutions.com/?ctx_ver= Z39.88-2004\&ctx_enc=info:ofi/enc:UTF8\&rfr_id=info:sid/ProQuest+Dissertations+ $\% 26+$ Theses+G.

Cornally, N., \& Mccarthy, G. (2011). Help-seeking behaviour: A concept analysis. International Journal of Nursing Practice, 17(3), 280-288. https://doi.org/10.1111/j.1440172X.2011.01936.x.

Eshita, I. R. (2018). Health problems and health care seeking behavior of street children in dhaka city. MOJ Cell Science \& Report, 5(1), 9-13.

https://doi.org/10.15406/mojcsr.2018.05.00 10

Fox, J. C., Blank, M., Rovnyak, V. G., \& Barnett, R. Y. (2001). Barriers to help seeking for mental disorders in a rural impoverished population. Community Mental Health Journal. https://Doi.Org/10.1023/A:1017580013197

Gorczynski, P., Sims-schouten, W., Hill, D., \& Wilson, J. C. (2017). Examining mental health literacy, help seeking behaviours, and mental health outcomes in UK university students. Journal of Mental Health Training, Education and Practice, 12(2), 111-120. https://doi.org/10.1108/JMHTEP-05-20160027.

Kaiser, E. (2020). Violence on street children: Looking through erikson's psychosocial development theory. Journal of Health and Social Sciences, 5(1), 45-52. https://doi.org/10.19204/2020/vlnc10

Kutcher, S., Wei, Y., \& Coniglio, C. (2016). Mental health literacy: Past, present, and future. Canadian Journal of Psychiatry, 61(3), 154158.

https://doi.org/10.1177/0706743715616609

Liang, B., Goodman, L., Tummala-Narar, P., \& Weintraub, S. (2005). A theoretical framework for understanding help-seeking processes among survivors of intimate partner violence. American Journal of Community Pyschology, 36(1/2). Doi: 10.1007/s10464005-6233-6, 71-84.

Lopez, V., Sanchez, K., Killian, M. O., \& Eghaneyan, B. H. (2018). Depression screening and education: An examination of 
mental health literacy and stigma in a sample of Hispanic women. BMC Public Health, 18(1), 1-8. https://doi.org/10.1186/s12889. 018-5516-4.

Nagai, S. (2015). Predictors of help-seeking behavior: Distinction between help-seeking intentions and help-seeking behavior. Japanese Psychological Research, 57(4), 313-322. https://doi.org/10.1111/jpr.12091.

Nihayah, E.S., \& Legowo, M. (2016). Eksploitasi anak jalanan (Studi kasus pada anak jalanan di surabaya). Jurnal Paradigma, 4 (1), 1-9. Retrieved from https://jurnalmahasiswa.unesa.ac.id/index.ph p/ paradigma/article/view/14094/12839

Pamungkas, \& Wisnu, W. 2018. Kemensos klaim jumlah anak jalanan tinggal 16.000 . Retrieved from https://Bandung.Bisnis.Com/Read/20181128 /549/1115072/Kemensos-Klaim-JumlahAnak-Jalanan-Tinggal-16.000.

Riebschleger, J., Grové, C., Cavanaugh, D., \& Costello, S. (2017). Mental health literacy content for children of parents with a mental illness: Thematic analysis of a literature review. Brain Sciences, 7(11). https://doi.org/10.3390/brainsci7110141.

Rio, A. P. 2019. Anak putus sekolah di palembang capai 1.278 orang. Retrieved from https://Wartamelayu.Com/Anak-PutusSekolah-Di-Palembang-Capai-1-278-Orang/.

Santrock, J.W. (2012). Life span development perkembangan masa hidup. (13 ed). Jakarta: Penerbit Erlangga.

Sugiyono. (2017). Metode penelitian kuantitatif, kualitatif, dan $r \& d$. Bandung : Alfabeta.

Tay, J. L., Tay, Y. F., \& Klainin-Yobas, P. (2018). Mental health literacy levels. Archives of Psychiatric Nursing, 32(5), 757-763. https://doi.org/10.1016/j.apnu.2018.04.007.

Tully, L. A., Hawes, D. J., Doyle, F. L., Sawyer, M. G., \& Dadds, M. R. (2019). A national child mental health literacy initiative is needed to reduce childhood mental health disorders. Australian and New Zealand Journal of Psychiatry, 53(4), 286-290. https://doi.org/10.1177/0004867418821440.

Umubyeyi, A., Mogren, I., Ntaganira, J., \& Krantz, G. (2016). Help-seeking behaviours, barriers to care and self-efficacy for seeking mental health care: A population-based study in rwanda. Social Psychiatry And Psychiatric Epidemiology. https://Doi.Org/10.1007/S00127-015-11302.
Undang-Undang Republik Indonesia Nomor 36 Tahun 2009 Kesehatan. 13 Oktober 2009. Lembaran Negara Republik Indonesia Tahun 2009 Nomor 5063. Jakarta.

Vina, Hergo. 2019. Perilaku sosial anak jalanan (Studi kasus anak jalanan di kota bandar lampung). Skripsi: Universitas Lampung. Retrieved from https://onesearch.id/Record/IOS4198.55610

Von Dem Knesebeck, O., Mnich, E., Daubmann, A., Wegscheider, K., Angermeyer, M. C., Lambert, M., Karow, A., Härter, M., \& Kofahl, C. (2013). Socioeconomic status and beliefs about depression, schizophrenia and eating disorders. Social Psychiatry and Psychiatric Epidemiology, 48(5), 775-782. https://doi.org/10.1007/s00127-012-0599-1.

Waldmann, T., Staiger, T., Oexle, N., \& Rüsch, N. (2019). Mental health literacy and helpseeking among unemployed people with mental health problems. Journal of Mental Health, 29(3), 270-276. https://doi.org/10.1080/09638237.2019.1581 342

Wardani, I. Y. (2018). Stres dan strategi koping anak jalanan di kota depok. Jurnal Persatuan Perawat Nasional Indonesia (Jppni), 2(2), 108-116. http://dx.doi.org/10.32419/jppni.v2i2.88

Wei, Y., McGrath, P. J., Hayden, J., \& Kutcher, S. (2015). Mental health literacy measures evaluating knowledge, attitudes and helpseeking: A scoping review. BMC Psychiatry, 15(291). https://doi.org/10.1186/s12888015-0681-9

Woan, J., Lin, J., \& Auerswald, C. (2013). The health status of street children and youth in low- and middle-income countries: A systematic review of the literature. Journal of Adolescent Health, 53(3), 314-321.e12. https://doi.org/10.1016/j.jadohealth.2013.03 .013 . 